\title{
The Application of Space Vector in Calculation of Plinth Elevation Angle
}

\author{
Fang Deng ${ }^{1, *},{ }^{*}$ Kai Peng ${ }^{1}$, Huanying Zeng ${ }^{1}$ and Dengbo $\mathrm{Li}^{1}$ \\ ${ }^{1}$ Powerchina Zhongnan Engineering Corporation Limited, Changsha, Hunan Province, 410014, China
}

\begin{abstract}
The plinth elevation angle was related to the upstream slope and face slab shape of CFRD, as well as to the dam axis, which was very important in plinth design. Based on the space vector algorithm, the function established consists of plinth elevation angle and three-dimensional coordinate of key points of plinth line, which was taken as the unique input variable, and then the plinth elevation angle was directly obtained. The improved vector method with characteristics of high efficiency, simple input parameters and clear spatial concept, is obviously superior to the traditional geometric method which was deduce by doing the auxiliary line, and it has been widely applied and well verified in engineering.
\end{abstract}

\section{Preface}

Plinth was very important in the design of concrete face rockfill dam. The inclined long section at the end of plinth was used as the starting working face in the face slab sliding mode construction, which was required to be in the same plane with the face slab. When the axis of the plinth (i.e. "X" line) was parallel to the dam axis, the elevation angle of the plinth was equal to the true angle of the face slab. In other cases, the elevation angle of the plinth must be calculated according to the spatial position of each plinth. [1,6]

Generally, the formula (2.4-1) in Volume 6 of hydraulic design manual (Second Edition) was used to calculate the elevation angle of plinth. The formula was as follows:[2]

$$
\cos (\theta)=\frac{m\left[(C-B)^{2}+L^{2}+m^{2}(C-B)^{2}\right]^{1 / 2}}{\left(1+m^{2}\right)^{1 / 2}\left(L^{2}+(C-B)^{2} m^{2}\right)^{1 / 2}}
$$

Where: $\mathrm{B}, \mathrm{C}$ - the height difference of $\mathrm{BC}$ segment of plinth.

$\mathrm{m}$ - the design slope of the face slab perpendicular to the dam axis;

$\mathrm{L}$ - the projection length of plinth AC section in the direction of dam axis;

There are many input parameters and complex formulas in this formula. It was easy to cause the calculation error of plinth elevation angle due to the incomplete quotation of the formula in practical engineering. [3 4]

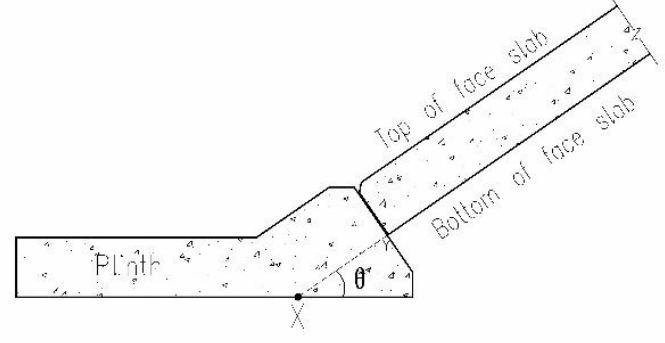

Figure 1. Cross section of plinth

\section{Deduce the common formula of plinth elevation angle}

The formula (2.4-1) in Volume 6 of hydraulic design manual (Second Edition) was shown in Figure 2.[5]

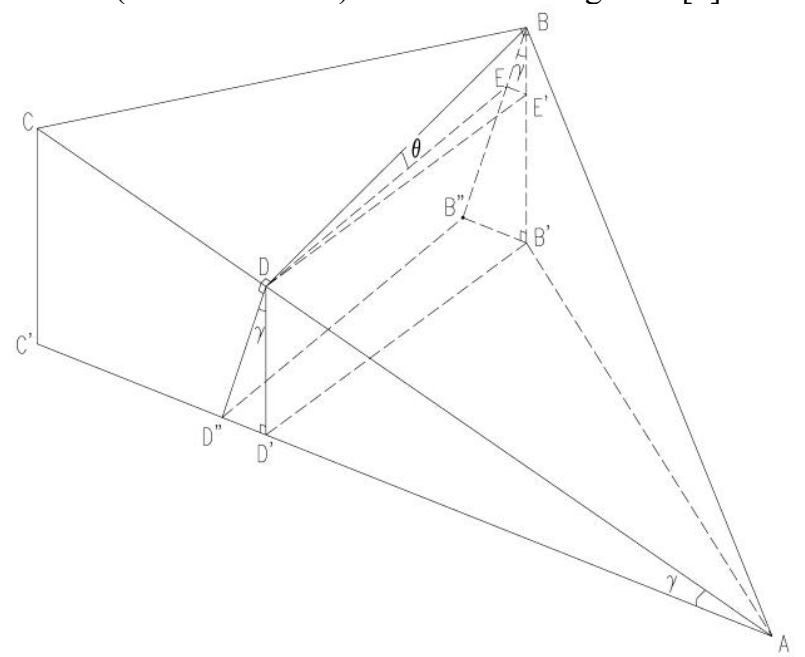

Figure 2. Geometric relationship of plinth elevation angle 
Taking the plinth of $\mathrm{AC}$ section in Figure 2 as an example, $\mathrm{BC}$ was parallel to the dam axis; $\mathrm{AB}$ was the dip line of the bottom of the face slab, and its slope ratio was 1: $\mathrm{m}$; $\mathrm{AC}$ was a segment on the X-ray of the plinth; Make a straight line $\mathrm{BD} \perp \mathrm{AC}$ through point $\mathrm{B}$ and intersect $\mathrm{AC}$ at point $\mathrm{D}$. Make a horizontal plane through point $\mathrm{A}$, and the vertical projection of $\mathrm{ABC}$ on the horizontal plane was $A B^{\prime} C^{\prime}$. The vertical projection of $B D$ was $B^{\prime} D^{\prime}$, and $\mathrm{DE}^{\prime} \| \mathrm{D}$ 'B ' was made through $\mathrm{D}$ point.

The vertical plane BDD "B" passing through BD was the intersection line of the vertical plane and the horizontal plane $\mathrm{AB}^{\prime} \mathrm{C}^{\prime}$. Make a straight line through $\mathrm{D}$ point $\mathrm{DE} \|$ $\mathrm{D}$ "B", $\angle \mathrm{BDE}=\theta$, was the elevation angle of plinth.

If two points $\mathrm{A}$ and $\mathrm{C}$ are known as the control points of plinth X-ray, the height difference of these two points can be calculated, and the projection length of these two points in the direction of dam axis can be measured on the drawing. The derivation process of the formula is as follows:

$$
\begin{aligned}
& B B^{\prime}=C C^{\prime}=H \\
& A B=H \sqrt{\left(1+m^{2}\right)} \\
& A C=\sqrt{A B^{2}+B C^{2}}=\sqrt{\left(1+m^{2}\right) H^{2}+L^{2}} \\
& B D \times A C=A B \times B C \\
& B D=\frac{A B \times L}{A C}=\frac{H L \sqrt{\left(1+m^{2}\right)}}{\sqrt{\left(1+m^{2}\right) H^{2}+L^{2}}} \\
& A D=\sqrt{A B^{2}-B D^{2}}=\frac{H^{2}\left(1+m^{2}\right)}{\sqrt{H^{2}\left(1+m^{2}\right)+L^{2}}} \\
& A C^{\prime}=\sqrt{A C^{2}-H^{2}}=\sqrt{m^{2} H^{2}+L^{2}} \\
& D D^{\prime}=\frac{A D \times H}{A C}=\frac{H^{3}\left(1+m^{2}\right)}{H^{2}\left(1+m^{2}\right)+L^{2}} \\
& E^{\prime} B^{\prime}=D D^{\prime} \\
& B E^{\prime}=B B^{\prime}-E^{\prime} B^{\prime}=H-\frac{H^{3}\left(1+m^{2}\right)}{H^{2}\left(1+m^{2}\right)+L^{2}} \\
& =\frac{H L^{2}}{H^{2}\left(1+m^{2}\right)+L^{2}} \\
& B E=\frac{B E^{\prime}}{\cos \gamma}=\frac{B E^{\prime} \times A C}{A C^{\prime}} \\
& =\frac{H L^{2}}{\sqrt{\left(\left(1+m^{2}\right) H^{2}+L^{2}\right)\left(m^{2} H^{2}+L^{2}\right)}} \\
& D E=\sqrt{D B^{2}-B E^{2}}=\frac{H m L}{\sqrt{m^{2} H^{2}+L^{2}}} \\
& \cos \theta=\frac{D E}{B D}=\frac{m \sqrt{\left(1+m^{2}\right) H^{2}+L^{2}}}{\sqrt{\left(1+m^{2}\right)} \sqrt{m^{2} H^{2}+L^{2}}}
\end{aligned}
$$

Where: $\mathrm{H}$ - the height difference of AC segment of plinth

$\mathrm{m}$ - the design slope of the face slab perpendicular to the dam axis

$\mathrm{L}$ - the projection length of plinth AC section in the direction of dam axis

The derived formula was consistent with that in hydraulic design manual. This formula was very complex, and it needs to draw several auxiliary lines to derive the formula.

\section{Deduce the formula of plinth elevation angle according to space vector method}

Only three control points on the "X" line of plinth are needed to calculate the elevation angle of plinth by vector method. Suppose there are three control points on the " $\mathrm{X}$ " line: $\mathrm{A}\left(\mathrm{x}_{\mathrm{A}}, \mathrm{y}_{\mathrm{A}}, \mathrm{z}_{\mathrm{A}}\right) 、 \mathrm{C}\left(\mathrm{x}_{\mathrm{C}}, \mathrm{y}_{\mathrm{C}}, \mathrm{z}_{\mathrm{C}}\right)$ and $\mathrm{K}\left(\mathrm{x}_{\mathrm{K}}, \mathrm{y}_{\mathrm{K}}\right.$, $\mathrm{Z}_{\mathrm{K}}$.

Taking the plinth of $\mathrm{AC}$ section in Figure 3 as an example, only the direction vectors of line segments DE and DB are needed to calculate the elevation angle of plinth.

The line segment DE was the intersection of the horizontal plane and the plane perpendicular to the plinth line, and the line segment DB was the intersection of the bottom surface of the panel and the plane perpendicular to the plinth line.

The vector of horizontal plane:

$\boldsymbol{n 1}=(0,0,1)$;

The vector of the plane perpendicular to the plinth line was the direction vector of the plinth line: $\boldsymbol{n} \mathbf{2}=\overrightarrow{\boldsymbol{A C}}$;

The vector of the face slab bottom can be calculated by any three " $\mathrm{X}$ " line control point coordinates: $\boldsymbol{n} \mathbf{3}=$ $\overrightarrow{A C} \times \overrightarrow{A K}$

Direction vector of DE: $\boldsymbol{s} \mathbf{1}=\boldsymbol{n} \mathbf{1} \times \boldsymbol{n} \mathbf{2}$;

Direction vector of DB: $\boldsymbol{s} \mathbf{2}=\boldsymbol{n} \mathbf{2} \times \boldsymbol{n} \mathbf{3}$;

Plinth elevation angle $\theta: \cos \theta=\frac{s \mathbf{s} 2}{|\boldsymbol{s 1}||\boldsymbol{s} 2|}$

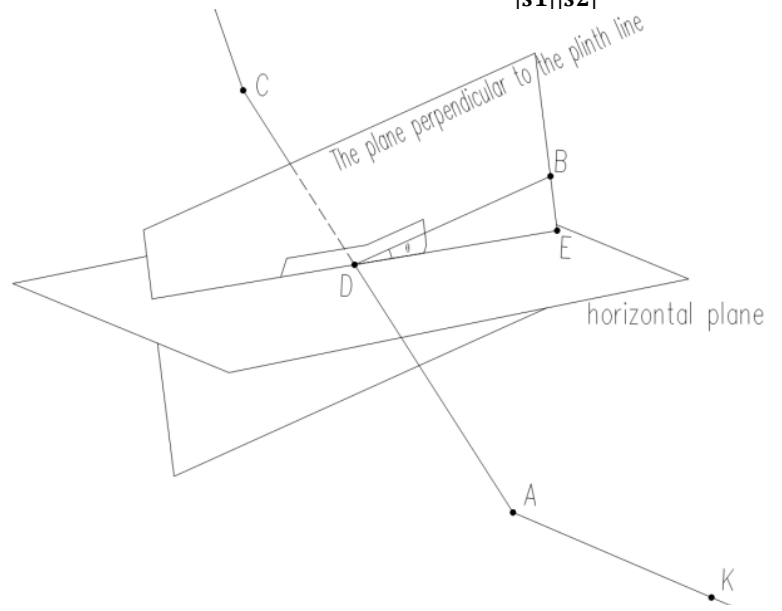

Figure 3. Plinth elevation angle by vector method

When the face slab was thickened, the angle between plinth and the top of slab can be calculated by space vector method.

It can be used to calculated the angle $\beta$ ( see

Figure 4) by way of the face slab top, the horizontal plane and the plane perpendicular to the plinth line .

The vector of the face slab top surface can be calculated by any three point coordinates, which were on the same projection plane as the control points on X-ray.

If the coordinate of a point $\mathrm{D}$ on the $\mathrm{X}$-ray was $\left(\mathrm{x}_{\mathrm{D}}\right.$, $\mathrm{y}_{\mathrm{D}}, \mathrm{z}_{\mathrm{D}}$ ), then the corresponding point $\mathrm{D}$ 'on the top of the face slab was $\left(x_{D}, y_{D}, z_{D}+h\right), h$ see formula (1). 


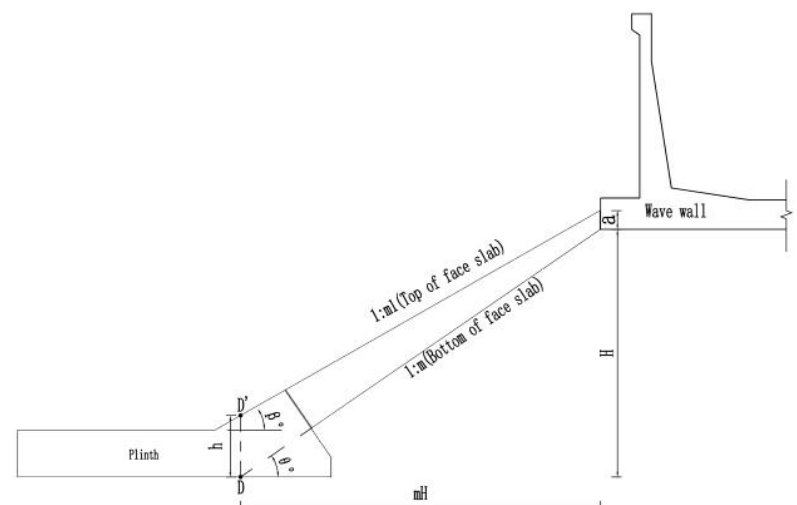

Figure 4. Section of thickened face slab $m H=m 1(H+a-h)$

$$
h=H+a-\frac{m}{m 1} H
$$

\section{Engineering verification}

There was a project with the slope ratio of the face slab bottom was $1: 1.45$, and the slope ratio of the face slab top was 1:1.456. The layout upstream plan of plinth was shown in Figure 5. The section of face slab and plinth was shown in Figure 6. The space vector method was used to calculate the elevation angle of plinth, and the results are shown in Table 1.

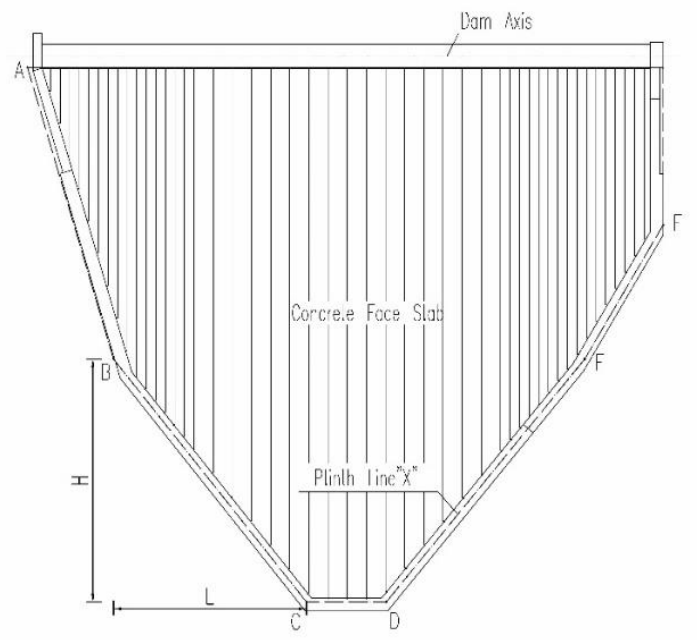

Figure 5. Layout upstream plan of plinth

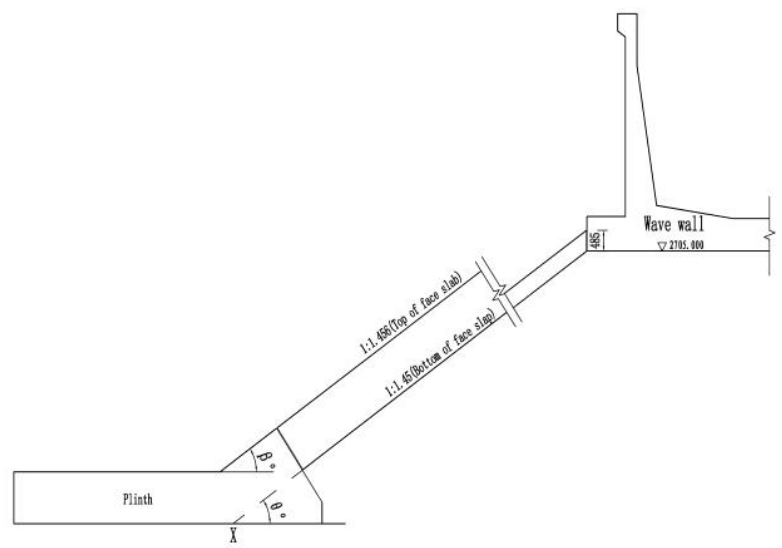

Figure 6. Section of face slab and plinth
Table1. Results of plinth elevation according to space vector

\begin{tabular}{|c|c|c|c|c|c|c|}
\hline Plinth & $\begin{array}{c}\text { "X" } \\
\text { Key } \\
\text { point }\end{array}$ & $X(m)$ & $Y(m)$ & $Z(m)$ & $\theta(9$ & $\begin{array}{l}\beta \\
(9 \\
\end{array}$ \\
\hline \multirow{2}{*}{$\begin{array}{c}\mathrm{AB} \\
\text { plinth }\end{array}$} & A & 3329852 & 504132 & 2706 & \multirow[t]{2}{*}{9.25} & \multirow[t]{2}{*}{9.22} \\
\hline & B & 3329938 & 503962 & 2580 & & \\
\hline \multirow{2}{*}{$\begin{array}{c}\mathrm{BC} \\
\text { plinth }\end{array}$} & B & 3329938 & 503962 & 2580 & \multirow[t]{2}{*}{20.68} & \multirow[t]{2}{*}{20.62} \\
\hline & $\mathrm{C}$ & 3329955 & 503768 & 2475 & & \\
\hline \multirow{2}{*}{$\begin{array}{l}\mathrm{CD} \\
\text { plinth }\end{array}$} & $\mathrm{C}$ & 3329955 & 503768 & 2475 & \multirow[t]{2}{*}{34.59} & \multirow[t]{2}{*}{34.48} \\
\hline & D & 3329918 & 503734 & 2475 & & \\
\hline \multirow{2}{*}{$\begin{array}{c}\text { DE } \\
\text { plinth }\end{array}$} & D & 3329918 & 503734 & 2475 & \multirow[t]{2}{*}{21.05} & \multirow[t]{2}{*}{20.99} \\
\hline & E & 3329723 & 503759 & 2580 & & \\
\hline \multirow{2}{*}{$\begin{array}{c}\text { EF } \\
\text { plinth }\end{array}$} & E & 3329723 & 503759 & 2580 & \multirow[t]{2}{*}{16.65} & \multirow[t]{2}{*}{16.60} \\
\hline & $\mathrm{F}$ & 3329630 & 503786 & 2638 & & \\
\hline
\end{tabular}

The formula (2.4-1) in Volume 6 earth rock dam of hydraulic design manual (Second Edition) was used to calculate the elevation angle of plinth. The results were shown in Table 2.

Table2. Results of plinth elevation by the formula hydraulic design manual

\begin{tabular}{ccccc}
\hline Plinth & $\boldsymbol{m}$ & $\boldsymbol{L}(\boldsymbol{m})$ & $\boldsymbol{H}(\boldsymbol{m})$ & $\boldsymbol{\theta}(\boldsymbol{9}$ \\
\hline AB plinth & 1.45 & 53.93 & 126 & 9.25 \\
BC plinth & 1.45 & 120.98 & 105 & 20.68 \\
CD plinth & 1.45 & 50.00 & 0 & 34.59 \\
DE plinth & 1.45 & 124.39 & 105 & 21.05 \\
EF plinth & 1.45 & 49.17 & 58 & 16.65 \\
\hline
\end{tabular}

It can be seen from the results in Table 1 and Table 2 that the results calculated by the formula derived by the space vector method are completely consistent with the results calculated by the formula recommended in the hydraulic design manual. The input parameter $m$ in Table 2 was known, $\mathrm{L}$ and $\mathrm{H}$ need to be measured on the drawing, and the input parameter in Table 1 was the " $X$ " point coordinate. When the face slab was thickened, the formula recommended in the hydraulic design manual cannot be calculated angle $\beta$.

\section{Conclusions}

(1)When the space vector method was used to deduce the formula of plinth elevation angle, the input parameters are simple, the space concept was clear, and the calculation accuracy was high.

(2)Compared with the traditional method of calculating plinth elevation angle by making auxiliary lines, it was greatly improved, and has been applied and verified in engineering.

(3) When the face slab was thickened, the angle between plinth and the top of slab can be calculated by space vector method. 


\section{References}

1. H.W.Xiao, Discussion on plinth design method of CFRD. Yangtze River 35, 27 (2004)

2. Z.C.Guan. Hydraulic design manual (Second Edition), China Water Power Press, 2014

3. G.C.Jiang ,Z.Fu,J.J.Feng. Concrete face rockfill dam engineering ,Hubei Science and Technology Publishing House, 1996

4. T.W.Zheng, Discussion on calculation formula of horizontal space angle of slab on cross section of toe slab. Low carbon world . 244 (2016)

5. M.X.Shu,Probe to calculation methods of CFRD toe board warping side angel of altitude.Journal of Gezhouba Institute of Hydro-Electric Engineering18 , 1 (1996)

6. X.J.Tang, Plinth layout and design of concrete face rockfill dam. Water power,29(1993) 